\title{
Label-free cell phenotypic profiling and pathway deconvolution of
}

\section{neurotensin receptor-1}

Tao Hou ${ }^{\mathrm{a}}$, Liying Shi ${ }^{\mathrm{b}}$, Jixia Wang ${ }^{\mathrm{a}}$, Lai Wei ${ }^{\mathrm{a}}$, Lala $\mathrm{Qu}^{\mathrm{a}}$, Xiuli Zhang*a,c and

$$
\text { Xinmiao Liang*a }
$$

${ }^{a}$ Key Laboratory of Separation Science for Analytical Chemistry, Dalian Institute of Chemical Physics, Chinese Academy of Sciences, Dalian, Liaoning 116023, China.

${ }^{b}$ Bioengineering College, Dalian University, Dalian, Liaoning 116622, China.

${ }^{c}$ Co-innovation Center of Neuroregeneration, Nantong University, Nantong, 226019,

China.

*Corresponding authors: liangxm@dicp.ac.cn (X.L.); zhangxiuli@dicp.ac.cn (X.Z.) 


\section{Abstract}

Neurotensin (NT), an endogenous peptide found in the central nervous system and in peripheral tissues, contributes to the pathophysiology of neurodegenerative and psychiatric diseases, cancer, inflammation, and immunomodulatory disease. NT exerts its physiological effects predominantly through its cognate high-affinity neurotensin receptor-1 (NTS1). NTS1 emerges as a druggable target; however, there are limited numbers of NTS1 active compounds reported to date. Here we reported a label-free cell phenotypic profiling model for screening NTS1 ligands and differentiating their biased agonism. Resonant waveguide grating enabled dynamic mass redistribution (DMR) assay was first optimized against cell confluency and then used to characterize the endogenous NTS1 in HT29 cell using known agonists and antagonists. Pathway modulators were also used to deconvolute the signaling pathways of endogenous NTS1. Results showed that the NTS1 DMR assay is robust for screening and can differentiate biased agonism; and the activation of NTS1 in HT29 triggers multiple pathways including $\mathrm{G}_{\mathrm{q}}$ signaling and epidermal growth factor receptor transactivation. This study highlighted the power of label-free DMR assay to characterize receptor signaling and pharmacology of distinct classes of ligands for NTS1, G protein-coupled receptors in general.

Keywords: Neurotensin receptor-1; Pathway; Label-free cell phenotypic profiling; Biased agonism 


\section{Introduction}

Neurotensin is an endogenous tridecapeptide found in the central nervous system (CNS) and in peripheral tissues, and exerts a wide range of physiological effects primarily through its high-affinity neurotensin receptor subtype 1 (NTS1). NTS1, a seven putative transmembrane $G$ protein-coupled receptor (GPCR), is highly expressed in the CNS and peripheral nervous system [1], and has been implicated in several important diseases including neurodegenerative and psychiatric diseases [1], cardiovascular diseases [2], and opioid-independent analgesic effects [3]. NTS1 is also expressed in several human neoplastic tissues, and has stimulatory proliferation, survival, pro-migratory and pro-invasive effects for multiple malignancies [4-7]. SR48692, a NTS1 antagonist, was found to significantly suppress tumor growth in xenograft models of colon and small cell lung cancer cells [8], and breast and non-small cell lung carcinomas (NSCLC) [9].

NTS1 is known to mediate multiple signaling pathways, as revealed using various cell models including murine neuroblastoma N1E-115 cells [10-12], human colon adenocarcinoma HT-29 cells [13], murine macrophage Raw264.7 cells [14], and overexpressed Chinese hamster ovary $(\mathrm{CHO})$ cells $[15,16]$. Several signaling pathways after NT stimulation are potentially involved in proliferation, survival, migration, and invasion processes of cancer cells. For example, NT activated NTS1 in KM20 cells, resulted in $\mathrm{Ca}^{2+}$ - and mitogen-activated protein kinase (MAPK) signaling pathways [17], while the activation of NTS1 in N1E115 cells resulted in cGMP $[18,19]$ and phospholipase C (PLC) activation [20,21]. In human prostate cancer cell line PC3, 
the activation of NTS1 by NT transactivates epidermal growth factor receptor (EGFR), an important receptor in cancer progression [22]. In human pancreatic cancer MIAPaCa-2 cells, both the ERK and Jun N-terminal kinase (JNK) pathway were activated [23-25]. In macrophages, JAK-STAT pathway was clearly involved in the neurotensin-activated NTS1 [26]. These results suggest that NTS1 is capable of mediating multiple signaling pathways in a cellular background sensitive manner.

Here, we described a label-free cell phenotypic profiling method to characterize ligand pharmacology and signaling of endogenous NTS1 in HT29 cells. This method uses resonant waveguide grating (RWG) biosensor system to non-invasively monitor ligand-induced dynamic redistribution of cellular mass in living cells, which enables holistic cell phenotypic measurement of ligand pharmacology and allows for systematic deconvolution of receptor signaling when combined with chemical biology approaches [27].

\section{Materials and Method}

\section{Compounds and reagents}

NT (Glp-Leu-Tyr-Glu-Asn-Lys-Pro-Arg-Arg-Pro-Tyr-Ile-Leu), NT8-13, JMV449 and GF109203X were obtained from Tocris Bioscience Co. (St. Louis, MO, USA). $\mathrm{NT}_{1-8}$ was purchased from GL Biochem Ltd (Shanghai). PD149163, SR48692, SR142948A, U73122, erlotinib, cyclopiazonic acid, Y27632, Tofacitinib and LY294002 were purchased from Sigma Chemical Co. (St Louis, MO, USA). Hank's balanced salt solution (HBSS), Hepes, fetal bovine serum (FBS) and McCoy's 5A medium were obtained from Sigma Chemical Co. (St. Louis, MO). 


\section{Cell culture}

Human colorectal adenocarcinoma HT-29 cells were obtained from the Type Culture Collection of the Chinese Academy of Science (Shanghai, China). HT-29 cells were cultured in McCoy's 5A medium supplemented with $10 \%$ FBS, $50 \mu \mathrm{g} / \mathrm{mL}$ penicillin and $100 \mu \mathrm{g} / \mathrm{mL}$ streptomycin at $37{ }^{\circ} \mathrm{C}$ under air $/ 5 \% \mathrm{CO}_{2}$. The cells were passed with trypsin/ethylene-diaminetetraacetic acid when approaching 90\% confluence to provide new maintenance culture on T-75 flasks and experimental culture on the biosensor microplates. For dynamic mass redistribution (DMR) assays, the cell seeding density was optimized when the culture duration in biosensor microplates was fixed to be $20 \mathrm{hrs}$.

\section{Dynamic mass redistribution assay}

DMR assays were carried out on an Epic ${ }^{\circledR}$ BT system (Corning, NY, USA). Unless specific mentioned, cells were directly seeded in Epic ${ }^{\circledR} 384$ biosensor microplate and cultured overnight to form a confluent monolayer in the cell culture medium. The cells were then manually washed twice, and maintained with the assay buffer (1× HBSS buffer, $10 \mathrm{mM}$ Hepes, $\mathrm{pH}$ 7.2) for $1 \mathrm{~h}$ before measurement.

For DMR agonism profiling, a 2-min baseline was first established, followed by adding compounds using the multi-channel pipette and recording the compound-triggered DMR signals for about $1 \mathrm{~h}$. For DMR antagonism or pathway deconvolution assays, cells were initially treated with either an antagonist, or a pathway modulator for $1 \mathrm{~h}$, respectively. Afterwards, the baseline was reestablished, followed by adding the known NTS1 agonists at a fixed dose (typically at its EC 80 or 
$\mathrm{EC}_{100}$ ) and monitoring the cellular responses induced by the agonists for $1 \mathrm{~h}$. NT dissolved in the assay buffer with $0.1 \%$ dimethyl sulfoxide (DMSO) and $0.1 \%$ bovine serum albumin (BSA). All DMR signals were background-corrected.

\section{Data analysis}

All data were analyzed by using GraphPad Prism 5.0 (GraphPad Software Inc., San Diego, CA, USA). All EC50 or $\mathrm{IC}_{50}$ were calculated based on the maximum amplitudes of DMR signals at 45 min after agonist stimulation unless otherwise stated. The $\mathrm{EC}_{50}$ values were obtained by fitting the dose DMR response curves with nonlinear regression. The $\mathrm{Z}^{\prime}$ factor was calculated using the formula of $[1-(3 \times \mathrm{CV}$ of the positive control $+3 \times \mathrm{CV}$ of the negative control) / (the mean of the positive control - the mean of the negative control)].

\section{Results}

\section{NT triggered a cell confluency sensitive DMR signal in HT29}

We first examined the sensitivity of NT-triggered DMR in HT29 to cell confluency. Since cell confluency is difficult to be accurately measured, we fixed the cell culture duration to $20 \mathrm{hrs}$ and varied the cell seeding density ranging from 5000 to 40,000 cells per well. Results showed that NT at $32 \mathrm{nM}$ triggered a cell seeding density dependent DMR (Fig.1A). The DMR maximum amplitude increased initially as the seeding density increased, until it reached a plateau when the cell seeding density exceed 20,000 cells per well. This was consistent with light microscopic imaging, showing that when the seeding density exceeds 20,000 cells per well overnight culture of HT29 all led to > 95\% confluency. Thus, all following assays 
were performed in HT29 cells with the seeding density at $3 \times 10^{4}$ cells per well.

A

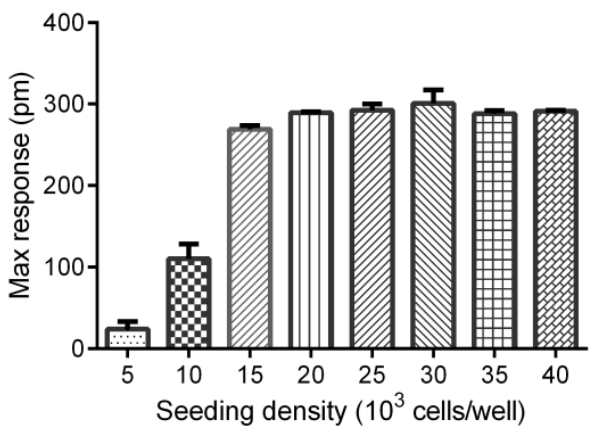

C

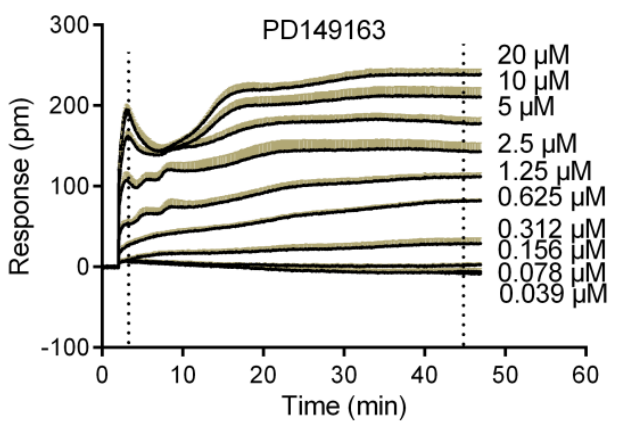

E

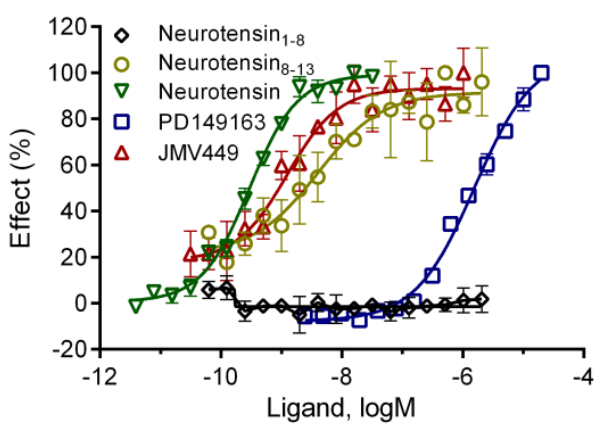

B

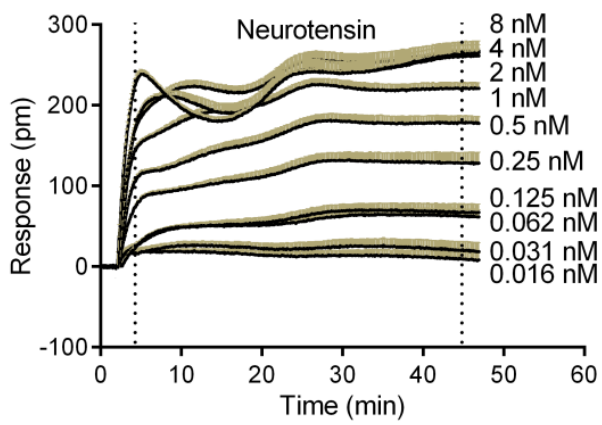

$\mathrm{D}$

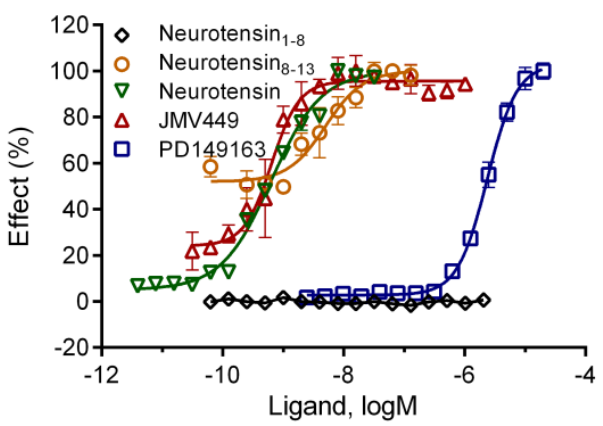

Fig. 1 The DMR responses of NTS1 ligands in HT-29 cells. (A) The maximum DMR responses of $32 \mathrm{nM}$ NT in HT-29 cells at different seeding density. (B, C) The real-time DMR dose responses of NT (B), or PD149163 (C). (D) The DMR amplitudes at 4 min post stimulation as a function of agonist dose. (E) The DMR amplitudes at 45 min post stimulation as a function of agonist dose. (A-E) cell culture time 20 hrs; (B-E) cell seeding density was 30,000 cells per well. The data represent mean \pm SD from 2 independent measurements, each in duplicate $(n=4)$. 


\section{NTS1 agonists display distinct time-dependent potency}

Next, we characterized several known NTS1 agonists-triggered DMR using DMR agonism assay. Result showed that NT triggered a robust DMR consisting of three phases: an initial fast increased DMR event (peak-DMR, P-DMR), a slow-decayed DMR event (valley-DMR, V-DMR) and a stable increased DMR (stable-DMR, S-DMR) (Fig.1B). NT8-13, JMV449, and PD149163 all triggered dose dependent DMR with similar characteristics (exemplified in Fig.1C). In contrast, the inactive fragment $\mathrm{NT}_{1-8}$ triggered little DMR, as expected. PD149163 and JMV449 are two $\mathrm{NT}_{8-13}$ analogues. These results are consistent with previous findings [28].

Based on the DMR characteristics, two time points (4 min and $45 \mathrm{~min}$ ) were used to fit the dose responses of the four NTS1 agonists examined (Fig.1D and E, Table 1). Results showed that as the post-stimulation time increased, the $\mathrm{EC}_{50}$ values of both NT and PD149163 slightly decreased, while the EC50 value of JMV449 slightly increased, but $\mathrm{NT}_{8-13}$ largely unchanged. One possibility is that distinct signal pathways contribute to the early and late event of the NTS1 DMR signals (see below), and different agonists may have different biased activities for these events [29]. This possibility is worthy of further investigation. 
Table 1 The EC50 value of NTSR agonists in HT-29 cells at two different time points.

\begin{tabular}{ccc}
\hline Agonist & \multicolumn{2}{c}{$\operatorname{EC}_{\mathbf{5 0}}(\mathbf{n}=\mathbf{4})$} \\
\cline { 2 - 3 } & $\mathbf{4} \mathbf{~ m i n}$ & $\mathbf{4 5} \mathbf{~ m i n}$ \\
\hline Neurotensin $(\mathbf{n M})$ & $0.63 \pm 0.04$ & $0.30 \pm 0.02$ \\
Neurotensin $\mathbf{1 - 8}(\mathbf{n M})$ & $/$ & $/$ \\
Neurotensin $_{\mathbf{8 - 1 3}}(\mathbf{n M})$ & $3.85 \pm 1.13$ & $4.02 \pm 1.27$ \\
PD149163( $\boldsymbol{\mu M})_{\mathbf{J M V 4 4 9}(\mathbf{n M})}$ & $2.36 \pm 0.07$ & $1.56 \pm 0.15$ \\
& $0.64 \pm 0.06$ & $1.25 \pm 0.25$ \\
\hline
\end{tabular}

\section{NTS1 DMR assay is robust}

Next, we assess the appropriateness of the NTS1 DMR assay for screening and pathway deconvolution study. Three parameters, including signal to noise ratio $(\mathrm{S} / \mathrm{N})$, $\mathrm{Z}$ ' factor and coefficient of variation $(\mathrm{CV})$, were evaluated using the DMR response from $2 \mathrm{nM} \mathrm{NT}\left(\mathrm{EC}_{100}\right)$ and $0.1 \mathrm{nM} \mathrm{NT}\left(\mathrm{EC}_{20}\right)$, respectively (Table 2). Results showed an averaged response of $6.67 \pm 8.75 \mathrm{pm}$ for the negative controls $(0.1 \%$ BSA and $0.1 \%$ DMSO in HBSS $)(\mathrm{n}=32), 97.49 \pm 6.91 \mathrm{pm}$ for $0.1 \mathrm{nM} \mathrm{NT}$ and $219.78 \pm 14.25 \mathrm{pm}$ for $2 \mathrm{nM} N T(\mathrm{n}=64)$. The $\mathrm{S} / \mathrm{N}$ ratios of $0.1 \mathrm{nM}$ and $2 \mathrm{nM}$ NT were found to be 11.65 and 15.18 , while the $\mathrm{CV}$ values were $7.09 \%$ and $6.48 \%$, and the $\mathrm{Z}$ ' factors were 0.5 and 0.68 , respectively. These results suggested that the NTS1 model in HT29 is appropriate for screening NTSR ligands using label-free cell phenotypic profiling. 
Table 2 The parameters for the NTS1 DMR assay model in HT29. The DMR responses were the maximum wavelength shifts of $0.1 \mathrm{nM}$ and $2 \mathrm{nM} \mathrm{NT}$ at $5 \mathrm{~min}$ after stimulation in HT29 cells with $3 \times 10^{4}$ cells per well. In this assay, the plate contained 32 wells of the negative controls (0.1\% BSA and 0.1\% DMSO in HBSS), 64 wells of positive agonist for $0.1 \mathrm{nM}$ NT and 64 wells of positive agonist for $2 \mathrm{nM}$ NT.

\begin{tabular}{|c|c|c|c|}
\hline & $\begin{array}{l}\text { Negative } \\
\text { control }\end{array}$ & $\begin{array}{c}0.1 \text { nM NT } \\
\left(\mathrm{EC}_{20}\right)\end{array}$ & $\begin{array}{c}2 \text { nM NT } \\
\left(\mathrm{EC}_{100}\right)\end{array}$ \\
\hline DMR response $(\mathrm{pm})$ & $6.67 \pm 8.75$ & $97.49 \pm 6.91$ & $219.78 \pm 14.25$ \\
\hline $\mathbf{S} / \mathbf{N}$ & / & 11.65 & 15.18 \\
\hline $\mathbf{C V}$ & I & $7.09 \%$ & $6.48 \%$ \\
\hline $\mathrm{Z}$ factor* & I & 0.50 & 0.68 \\
\hline
\end{tabular}

* The Z-factor is a measure of statistical effect size. It has been proposed for use in high-throughput screening (where it is also known as Z-prime, and commonly written as $Z^{\prime}$ ) to judge whether the response in a particular assay is large enough to warrant further attention.

\section{The NT-induced DMR is specific to the activation of NTS1}

Next, we examined the specificity of the NT-induced DMR to NTS1 using DMR antagonist assay, which examined the effects of known NTS1 antagonists (SR48692 and SR142948A [30]) on the NT DMR signal. Results showed that both SR48692 and SR142948A dose-dependently and completely inhibited the DMR signal of NT, leading to an apparent $\mathrm{IC}_{50}$ of $4.70 \pm 0.43$ and $0.30 \pm 0.01 \mu \mathrm{M}(\mathrm{n}=4)$, respectively (Fig.2A). Similar results were obtained for the DMR of PD149163 with similar IC50 values $(2.35 \pm 0.16$ vs $0.17 \pm 0.02 \mu \mathrm{M}(\mathrm{n}=4)$ for SR48692 and SR142948A, 
respectively) (Fig.2B). These results suggest that the DMR arising from agonists is specific to the activation of NTS1. These apparent $\mathrm{IC}_{50}$ values were higher than their corresponding in the binding assays [31], but consistent with many cell-based results [32].
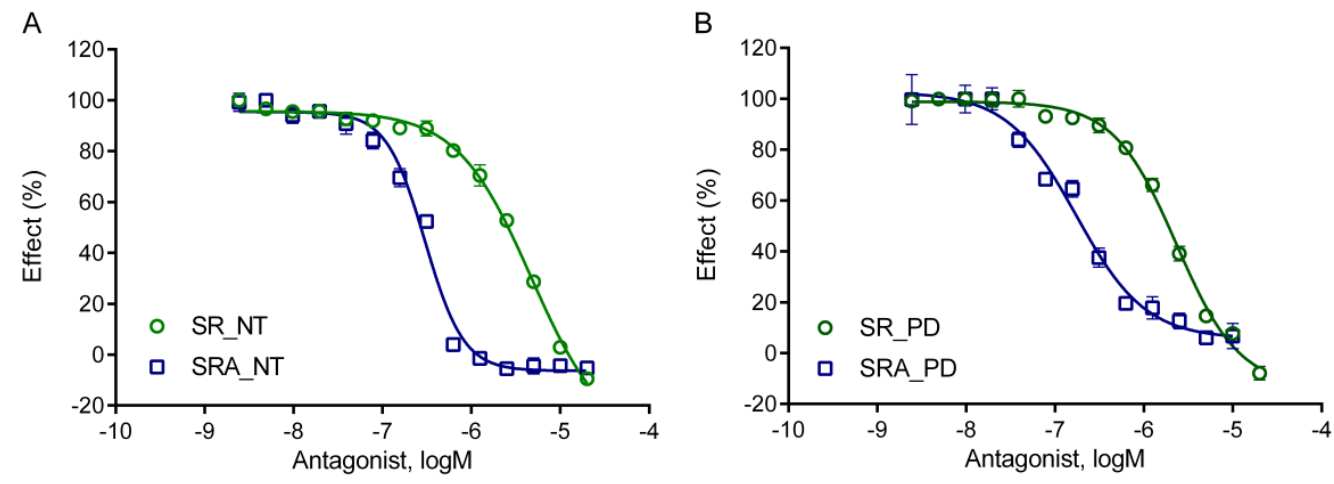

Fig. 2 Inhibition profiles of two antagonists on the DMR signal of $4 \mathrm{nM}$ NT and 20 $\mu \mathrm{M}$ PD in HT-29 cells. (A) The dose-dependent inhibition of NT induced by the known NTSR antagonist SR and SRA. (B) The dose-dependent inhibition of PD induced by the known NTSR antagonist SR and SRA. The data represent mean \pm SD from 2 independent measurements, each in duplicate $(n=4)$. SR represents SR48692. SRA represents SR142948A. NT represents neurotensin. PD represents PD149163.

\section{NTS1 activates multiple pathways}

Finally, we examined the signaling pathways of NTS1 in HT29 cells using DMR pathway deconvolution assay, which examine the effects of the pretreatment of cells with different pathway modulators on the DMR induced by NT or PD149163. Results showed that the phospholipase C (PLC) inhibitor U73122 dose-dependently and completely inhibited both DMR signals. The sarco/endoplasmic reticulum $\mathrm{Ca}^{2+}$-ATPase (SERCA) specific inhibitor cyclopiazonic acid completely inhibited the 
DMR of NT, but partially the DMR of PD149163 (Fig.3). The Janus kinase (JAK) inhibitor tofacitinib only partially inhibited the DMR of both agonists (Fig.3). The ROCK inhibitor Y27632 partially inhibited the DMR of NT, but almost completely the DMR of PD149163 (Fig.4). Similar results were observed for the PI3K inhibitor LY294002, and the protein kinase C inhibitor GF109203X (Fig.4). In contrast, the EGFR inhibitor erlotinib almost completely inhibited the late DMR of both NT and PD149163, but partially the early DMR of both agonists (Fig.4). Taken together, these results suggest that the activation of NTS1 triggers $\mathrm{G}_{\mathrm{q}}-\mathrm{PLC}-\mathrm{Ca}^{2+}-\mathrm{PKC}$ pathway, JAK pathway, ROCK pathway, and EGFR transactivation, and the EGFR transactivation primarily contributes to the late DMR signal event. Furthermore, the different sensitivity of the NT and PD149163 DMR to distinct pathway modulators indicates their biased agonism. Additionally, some inhibitors may display a higher $\mathrm{IC}_{50}$ value than ones in the other assay. For example, erlotinib is known to inhibit EGF receptor signaling with $2 \mathrm{nM}$ of $\mathrm{IC}_{50}$ [33]. This is because our method is based on cellular level. Cell uptake of inhibitors is a relatively slow process. The intracellular of inhibitors concentration depends on the amount of inhibitor added and the time of cell uptake, which is generally lower than that in the assay solution [34]. And the cell retention of inhibitors is a function of cell uptake and effluxing. The inhibitor effluxing can be accomplished through effluxing transporter such as ATP binding cassette subfamily G member 2 (ABCG2) [35]. Therefore, inhibitors may display a higher $\mathrm{IC}_{50}$ value to block the DMR responses. For example, erlotinib has been reported to inhibit the EGF responses with the $\mathrm{IC}_{50}$ of $11.7 \mu \mathrm{M}$ [34]. 

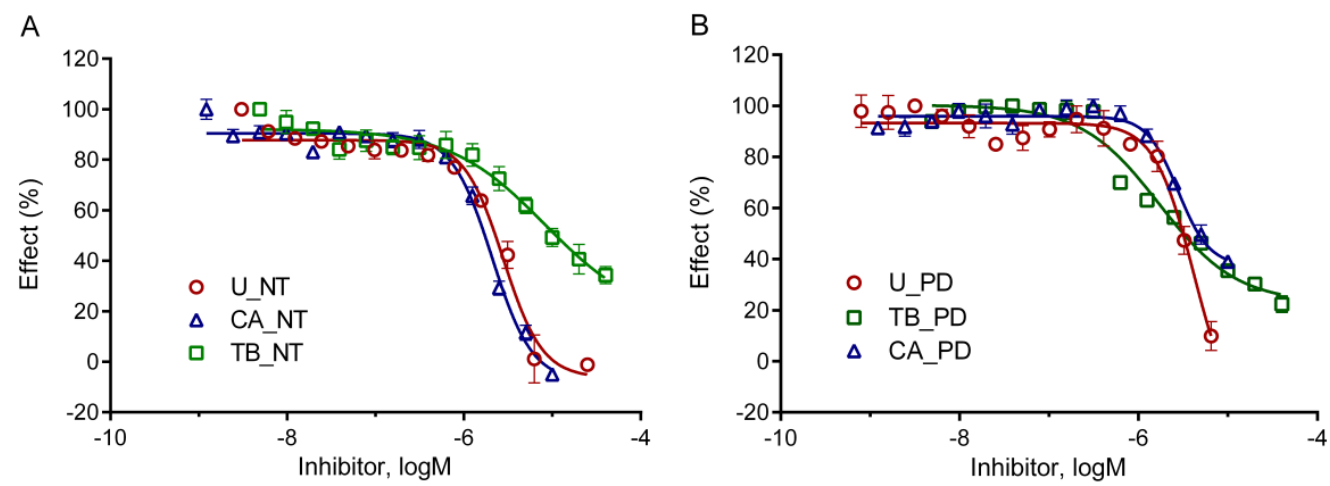

Fig. 3 The effects of pathway inhibitors on the DMR signal of $4 \mathrm{nM}$ NT and $20 \mu \mathrm{M}$ PD in HT-29 cells. A: Dose-dependent inhibition of the NT DMR by U73122, cyclopiazonic acid and tofacitinib. B: Dose-dependent inhibition of the PD DMR by U73122, cyclopiazonic acid and tofacitinib. The data represent mean \pm SD from 2 independent measurements, each in duplicate $(n=4)$. NT represents neurotensin. PD represents PD149163. U represents U73122. CA represents cyclopiazonic acid. TB represents tofacitinib.

Table 3 The $\mathrm{IC}_{50}$ for the effect of pathway inhibitors on the DMR at $45 \mathrm{~min}$ post-stimulation of NT and PD149163 in HT-29 cells.

\begin{tabular}{ccc}
\hline Inhibitor & NT (IC50) & PD149163 (IC50) \\
\hline U73122 $(\boldsymbol{\mu M})$ & $3.52 \pm 0.95$ & $6.60 \pm 3.64$ \\
Cyclopiazonic acid $(\boldsymbol{\mu M})$ & $2.09 \pm 0.14$ & $2.76 \pm 0.19$ \\
Tofacitinib $(\boldsymbol{\mu M})$ & $9.22 \pm 3.98$ & $1.71 \pm 0.24$ \\
Erlotinib $(\boldsymbol{\mu M})$ & $9.67 \pm 1.55$ & $7.83 \pm 4.20$ \\
Y27632 $(\boldsymbol{\mu M})$ & $20.38 \pm 4.16$ & $25.45 \pm 4.07$ \\
LY294002 $(\boldsymbol{\mu M}) *$ & $/$ & $/$ \\
GF109203X $(\boldsymbol{\mu M}) *$ & $/$ & \\
\hline
\end{tabular}

* IC50 values are not calculated because they are larger than $100 \mu \mathrm{M}$. 

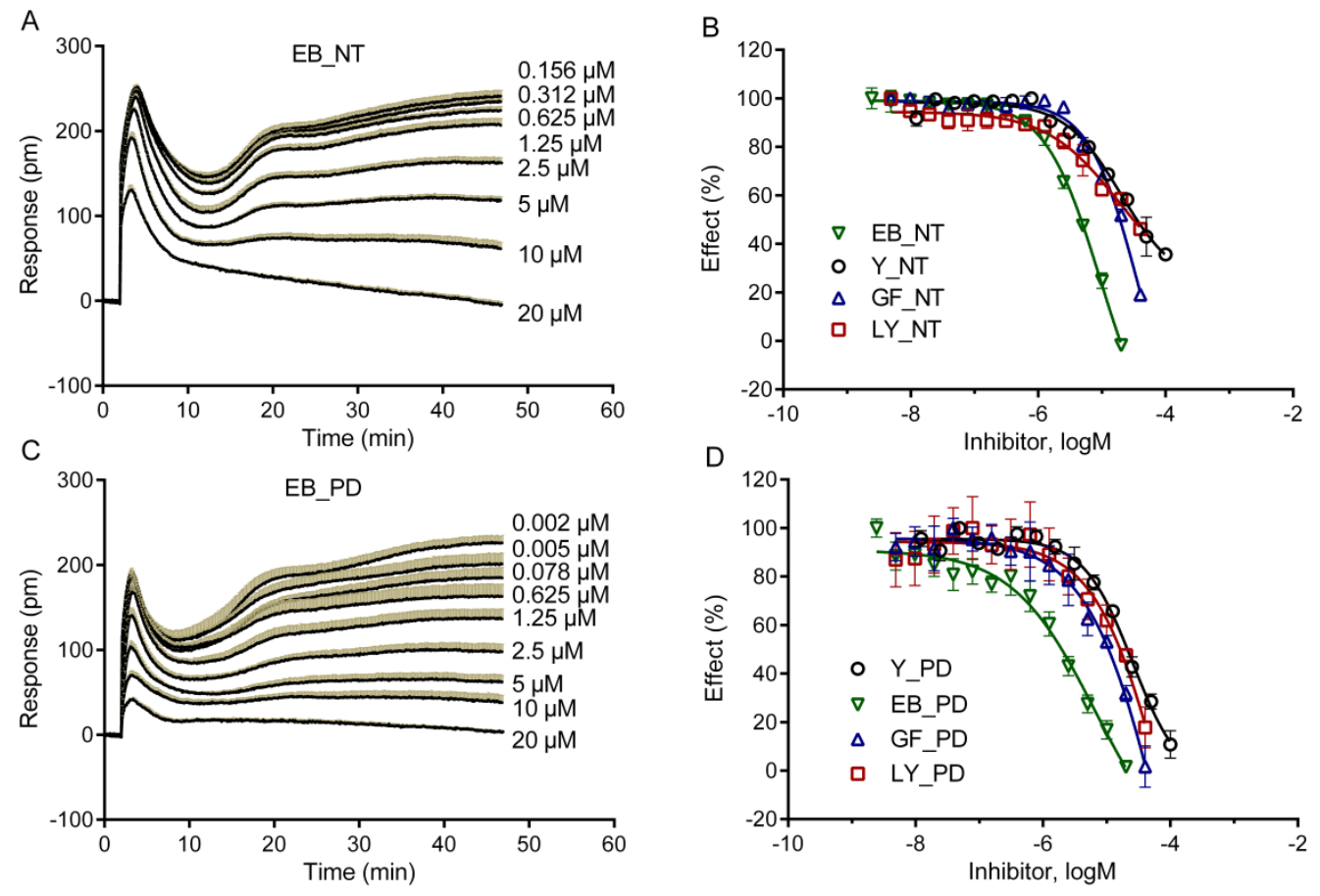

Fig. 4 The effects of kinase inhibitors on the DMR signals of $4 \mathrm{nM}$ NT and $20 \mu \mathrm{M}$ PD in HT-29 cells. A and C: The DMR of NT (A) and PD (C) after $1 \mathrm{~h}$ pretreatment with erlotinib at different doses. B and D: Dose-dependent inhibition of the NT (B) and PD (D) DMR by the kinase inhibitors Y27632, LY294002, erlotinib and GF109203X. The data represent mean \pm SD from 2 independent measurements, each in duplicate $(\mathrm{n}=$ 4). NT represents neurotensin. PD represents PD149163. EB represents erlotinib. Y represents Y27632. GF represents GF109203X. LY represents LY294002.

\section{Discussion}

The neurotensin and neurotensin receptor system has been shown to enhance cancer progression in various cancers such as pancreatic [36], prostate [37,38], lung [39], breast [40], and colon cancer [41]. NTS1 is also known to trigger multiple oncogenic signaling pathways, such as the PKC/ERK and AKT pathways 
$[22,25,26,42]$. The discovery of NTS1 antagonists holds promise in developing novel oncology drugs. Given that label-free DMR assay has high sensitivity to probe receptor biology $[43,44]$ and high throughput for screening of compounds against endogenous receptors [45], we attempt to develop a robust assay using native cancer cells to discover novel ligands for NTS1, and to deconvolute signaling pathways. Understanding the pathways contributing to the DMR signature of NTS1 activation is essential to identify pathway biased ligands for the receptor.

DMR assays showed that endogenous NTS1 in HT29 is functional, whose activation by four known agonists, NT, NT8-13, PD149163 and JMV449, all triggered robust DMR signals. These agonism DMR signals can be inhibited by two NTSR antagonists (SR48692 and SR142948A), suggesting that the DMR of NTS1 agonists is specific to the NTS1 activation. Pathway deconvolution by combining DMR assay with chemical biology probe molecules suggests that NTS1 in HT29 is capable of triggering multiple signaling pathways including $\mathrm{G}_{\mathrm{q}}-\mathrm{PLC}-\mathrm{Ca}^{2+}-\mathrm{PKC}$ pathway, JAK pathway, ROCK pathway, and EGFR transactivation. Previously, Turner et al. demonstrated a polyphosphoinositide-[Ca $\left.{ }^{2+}\right]$ pathway in HT-29 cells when stimulated with NT $[13,46]$. PKC, as a result of activation of PLC via DAG and $\mathrm{Ca}^{2+}$ [22], is also known to be involved in NT-induced EGFR transactivation and DNA synthesis [47-49]. JAK pathway has been implicated in immunosuppressive and anti-inflammatory activity $[26,50]$. Notably, the present study also discovered how these pathways work cooperatively to contribute to the overall DMR signal arising from the activation of NTS1; for instance, NTS1 transactivates EGFR, contributing primarily to the late 
DMR event. In HT-29 cells, neurotensin-induced activation of ERK was PKC-dependent, whereas activation of the PI3K/Akt pathway was mediated by subsequent transactivation of the EGFR. NT has the ability to promote cancer cell migration and invasion, but the molecular mechanism remains unclear. Previous studies showed that NT could regulate the activity of Rho-guanosine 3 phosphatase 1 (Rac1), Ras homolog family member A (RhoA) and cell division cycle 42 [5,51-53]. These proteins are involved in the dynamic balance of the cytoskeleton, then to promote the formation of pseudopodia, lamellipodia, filopodia and invadopodia via cytoplasmic extension. Activation of RhoA leads to ROCK-dependent activation of downstream pathway, resulting in cell migration [5]. Our results suggest that ROCK pathway is also involved in NTS1 signaling, which provides insight about molecular mechanism for NTS1 mediating cancer cell migration and invasion. In addition, the PLC pathway and RhoA-ROCK pathway have a cross talk with each other [54-56]. Therefore, ROCK inhibitor Y27632 and PLC inhibitor U73122 attenuated the NT-induced DMR signals due to a heterogeneous desensitization.

In summary, we established a model for screening NTS1 ligands and studying the mechanism of action of NTS1 agonists in HT-29 cells using label-free DMR assays. Our results systematically validated the NT signaling pathways including: (a) activation of PLC, PI3K and PKC dependent pathway; (b) activation of JAK-STAT signaling pathway; (c) crosstalk with EGFR; and (d) activation of ROCK. This model would greatly improve the efficiency for screening NTS1 ligands and presents a good starting point to design and optimize new NTS1 ligands for drug development. This 
research also exhibited the powerful potential of DMR assays in the study of receptor biology in living cells.

There are no drugs which target on NTS1, but NTS1 has the potential to be a great drug target because of its physiological functions. High throughput screening is crucial to drug discovery and development, owing to the increasing numbers of druggable targets and the increasing size of compound library. Label-free cell phenotypic assays hold great potentials in high throughput screening. It can often result in potential false negatives due to the pathway biased nature, as well as high false positives because of labeled or engineered cell. However, label-free cell phenotypic assays offer non-invasive alternative to assay endogenous neurotensin receptor and other GPCRs in native cells. This method can monitor drug-induced DMR with multiplexing $[57,58]$ and multi-modes $[59,60]$, unlike conventional assays that often just provide a single detection indicator such as calcium fluxes or membrane potential. The establishment of label-free cell phenotypic profiling model can improve the screening efficiency of leading compounds for NTS1, and useful for studying the pharmacological mechanism of NTS1.

\section{Acknowledgements}

This work was funded by "Project of National Science Foundation of China (81473436)" and "Project of International Cooperation Plan Ministry of Science and Technology of China (2015DFG32260)". 


\section{Reference}

[1] Tanaka K, Masu M, Nakanishi S, Structure and functional expression of the cloned rat neurotensin receptor, Neuron. 4 (1990) 847-854.

[2] Osadchii OE, Emerging role of neurotensin in regulation of the cardiovascular system, Eur. J. Pharmacol. 762 (2015) 184-192.

[3] Feng YP, Wang J, Dong YL, Wang YY, Li YQ, The roles of neurotensin and its analogues in pain, Curr. Pharm. Design. 21 (2015) 840-848.

[4] Souaze F, Viardot-Foucault V, Roullet N, Toy-Miou-Leong M, Gompel A, Bruyneel E, Comperat E, Faux MC, Mareel M, Rostene W, Flejou JF, Gespach C, Forgez $\mathrm{P}$, Neurotensin receptor 1 gene activation by the tcf/beta-catenin pathway is an early event in human colonic adenomas, Carcinogenesis. 27 (2006) 708-716.

[5] Dupouy S, Mourra N, Doan VK, Gompel A, Alifano M, Forgez P, The potential use of the neurotensin high affinity receptor 1 as a biomarker for cancer progression and as a component of personalized medicine in selective cancers, Biochimie. 93 (2011) 1369-1378.

[6] Morgat C, Mishra AK, Varshney R, Allard M, Fernandez P, Hindie E, Targeting neuropeptide receptors for cancer imaging and therapy: Perspectives with bombesin, neurotensin, and neuropeptide-y receptors, J. Nucl. Med. 55 (2014) 1650-1657.

[7] Myers RM, Shearman JW, Kitching MO, Ramos-Montoya A, Neal DE, Ley SV, Cancer, chemistry, and the cell: Molecules that interact with the 
neurotensin receptors, Acs. Chem. Biol. 4 (2009) 503-525.

[8] Moody TW, Chiles J, Casibang M, Moody E, Chan D, Davis TP, Sr48692 is a neurotensin receptor antagonist which inhibits the growth of small cell lung cancer cells, Peptides. 22 (2001) 109-115.

[9] Alifano M, Souaze F, Dupouy S, Camilleri-Broet S, Younes M, Ahmed-Zaid SM, Takahashi T, Cancellieri A, Damiani S, Boaron M, Broet P, Miller LD, Gespach C, Regnard JF, Forgez P, Neurotensin receptor 1 determines the outcome of non-small cell lung cancer, Clin. Cancer. Res. 16 (2010) 4401-4410.

[10] Yamada M, Yamada M, Richelson E, Role of signal-transduction systems in neurotensin receptor down-regulation induced by agonist in murine neuroblastoma clone n1e-115 cells, J. Pharmacol. Exp. Ther. 267 (1993) 128-133.

[11] Yamada M, Yamada M, Richelson E, Further characterization of neurotensin receptor desensitization and down-regulation in clone n1e-115 neuroblastoma-cells, Biochem. Pharmacol. 45 (1993) 2149-2154.

[12] Yamada M, Yamada M, Richelson E, Block of neurotensin receptor down-regulation by an aminosteroid in n1e-115 cells, Eur. J. Pharm-Molec. Ph. 226 (1992) 187-188.

[13] Turner JT, Jameskracke MR, Camden JM, Regulation of the neurotensin receptor and intracellular calcium mobilization in ht29 cells, J. Pharmacol. Exp. Ther. 253 (1990) 1049-1056. 
[14] Moura LIF, Silva L, Leal EC, Tellechea A, Cruz MT, Carvalho E, Neurotensin modulates the migratory and inflammatory response of macrophages under hyperglycemic conditions, Biomed. Res. Int. (2013)

[15] Hermans E, Gailly P, Gillis JM, Octave JN, Maloteaux JM, Lack of rapid desensitization of $\mathrm{Ca}^{2+}$ responses in transfected cho cells expressing the rat neurotensin receptor despite agonist-induced internalization, J. Neurochem. 64 (1995) 2518-2525.

[16] Pausch M, Lai M, Kopsco D, Popiolek M, Tseng E, Neurotensin nts1 receptor - g protein coupling selectivity characterized by expression in cho and yeast cells, Int. J. Neuropsychoph. 7 (2004) S469-S469.

[17] Ehlers RA, Bonnor RM, Wang XF, Hellmich MR, Evers BM, Signal transduction mechanisms in neurotensin-mediated cellular regulation, Surgery. 124 (1998) 239-246.

[18] Yamada M, Yamada M, Watson MA, Richelson E, Neurotensin stimulates cyclic-amp formation in cho-rntr-10 cells expressing the cloned rat neurotensin receptor, Eur. J. Pharm-Molec. Ph. 244 (1993) 99-101.

[19] Hasegawa K, Kar S, Carr BI, Stimulation of hepatocyte DNA-synthesis by neurotensin, J. Cell. Physiol. 158 (1994) 215-222.

[20] Hermans E, Maloteaux JM, Mechanisms of regulation of neurotensin receptors, Pharmacol. Therapeut. 79 (1998) 89-104.

[21] Amar S, Kitabgi P, Vincent JP, Stimulation of inositol phosphate production by neurotensin in neuroblastoma-n1e115 cells - implication of gtp-binding 
proteins and relationship with the cyclic-gmp response, J. Neurochem. 49 (1987) 999-1006.

[22] Hassan S, Dobner PR, Carraway RE, Involvement of map-kinase, pi3-kinase and egf-receptor in the stimulatory effect of neurotensin on DNA synthesis in pc3 cells, Regul. Pept. 120 (2004) 155-166.

[23] Minden A, Karin M, Regulation and function of the jnk subgroup of map kinases, Bba-Rev. Cancer. 1333 (1997) F85-F104.

[24] Seger R, Krebs EG, Protein kinases .7. The mapk signaling cascade, Faseb. J. 9 (1995) 726-735.

[25] Ehlers RA, Zhang Y, Hellmich MR, Evers BM, Neurotensin-mediated activation of mapk pathways and ap-1 binding in the human pancreatic cancer cell line, mia paca-2, Biochem. Biophys. Res. Commun. 269 (2000) 704-708.

[26] Kim HS, YumkhaM S, Choi JH, Lee SH, Kim TH, Ryu SH, Suh PG, Neurotensin enhances nitric oxide generation via the jak2-stat1 pathway in murine macrophage raw264.7 cells during costimulation with lps and ifn gamma, Neuropeptides. 40 (2006) 221-229.

[27] Fang Y, Label-free drug discovery, Front. Pharmacol. 5 (2014)

[28] Wustrow DJ, Davis MD, Akunne HC, Corbin AE, Wiley JN, Wise LD, Heffner TG, Reduced amide bond neurotensin 8-13 mimetics with potent in vivo activity, Bioorg. Med. Chem. Lett. 5 (1995) 997-1002.

[29] Deng HY, Sun HY, Fang Y, Label-free cell phenotypic assessment of the biased agonism and efficacy of agonists at the endogenous muscarinic m-3 
receptors, J. Pharmacol. Tox. Met. 68 (2013) 323-333.

[30] Thomas JB, Navarro H, Warner KR, Gilmour B, The identification of nonpeptide neurotensin receptor partial agonists from the potent antagonist sr48692 using a calcium mobilization assay, Bioorg. Med. Chem. Lett. 19 (2009) 1438-1441.

[31] Gully D, Canton M, Boigegrain R, Jeanjean F, Molimard JC, Poncelet M, Gueudet C, Heaulme M, Leyris R, Brouard A, Pelaprat D, Labbejullie C, Mazella J, Soubrie P, Maffrand JP, Rostene W, Kitabgi P, Lefur G, Biochemical and pharmacological profile of a potent and selective nonpeptide antagonist of the neurotensin receptor, P. NATL. ACAD. SCI. USA. 90 (1993) 65-69.

[32] Zhang Y, Zhu S, Yi L, Liu Y, Cui H, Neurotensin receptor 1 antagonist sr48692 reduces proliferation by inducing apoptosis and cell cycle arrest in melanoma cells, Mol. Cell. Biochem. 389 (2014) 1-8.

[33] Moyer JD, Barbacci EG, Iwata KK, Arnold L, Boman B, Cunningham A, DiOrio C, Doty J, Morin MJ, Moyer MP, Neveu M, Pollack VA, Pustilnik LR, Reynolds MM, Sloan D, Theleman A, Miller P, Induction of apoptosis and cell cycle arrest by cp-358,774, an inhibitor of epidermal growth factor receptor tyrosine kinase, Cancer. Res. 57 (1997) 4838-4848.

[34] Deng H, Wang C, Fang Y, Label-free cell phenotypic assessment of the molecular mechanism of action of epidermal growth factor receptor inhibitors, RSC. Adv. 3 (2013) 10370. 
[35] Imai Y, Nakane M, Kage K, Tsukahara S, Ishikawa E, Tsuruo T, Miki Y, Sugimoto Y, C421a polymorphism in the human breast cancer resistance protein gene is associated with low expression of q141k protein and low-level drug resistance, Mol. Cancer. Ther. 1 (2002) 611-616.

[36] Feurle GE, Muller B, Rix E, Neurotensin induces hyperplasia of the pancreas and growth of the gastric antrum in rats, Gut. 28 (1987) 19-23.

[37] Seethalakshmi L, Mitra SP, Dobner PR, Menon M, Carraway RE, Neurotensin receptor expression in prostate cancer cell line and growth effect of nt at physiological concentrations, Prostate. 31 (1997) 183-192.

[38] DaSilva JO, Amorino GP, Casarez EV, Pemberton B, Parsons SJ, Neuroendocrine-derived peptides promote prostate cancer cell survival through activation of igf-1r signaling, Prostate. 73 (2013) 801-812.

[39] Younes M, Wu ZR, Dupouy S, Lupo AM, Mourra N, Takahashi T, Flejou JF, Tredaniel J, Regnard JF, Damotte D, Alifano M, Forgez P, Neurotensin (nts) and its receptor (ntsr1) causes egfr, her2 and her3 over-expression and their autocrine/paracrine activation in lung tumors, confirming responsiveness to erlotinib, Oncotarget. 5 (2014) 8252-8269.

[40] Somai S, Gompel A, Rostene W, Forgez P, Neurotensin counteracts apoptosis in breast cancer cells, Biochem. Biophys. Res. Commun. 295 (2002) 482-488.

[41] Kamimae S, Yamamoto E, Kai M, Niinuma T, Yamano H, Nojima M, Yoshikawa K, Kimura T, Takagi R, Harada E, Harada T, Maruyama R, Sasaki Y, Tokino T, Shinomura Y, Sugai T, Imai K, Suzuki H, Epigenetic silencing of 
ntsr1 is associated with lateral and noninvasive growth of colorectal tumors, Oncotarget. 6 (2015) 29975-29990.

[42] PoinotChazel G, Portier M, Bouaboula M, Vita N, Pecceu F, Gully D, Monroe JG, Maffrand JP, LeFur G, Casellas P, Activation of mitogen-activated protein kinase couples neurotensin receptor stimulation to induction of the primary response gene krox-24, Biochem. J. 320 (1996) 145-151.

[43] Fang Y, Ferrie AM, Fontaine NH, Yuen PK, Characteristics of dynamic mass redistribution of epidermal growth factor receptor signaling in living cells measured with label-free optical biosensors, Anal. Chem. 77 (2005) $5720-5725$.

[44] Fang Y, Li GS, Peng JL, Optical biosensor provides insights for bradykinin b-2 receptor signaling in a431 cells, Febs. Lett. 579 (2005) 6365-6374.

[45] Li G, Ferrie AM, Fang Y, Label-free profiling of ligands for endogenous gpcrs using a cell-based high-throughput screening technology, J. Assoc. Lab. Autom. 11 (2006) 181-187.

[46] Martin S, Navarro V, Vincent JP, Mazella J, Neurotensin receptor-1 and -3 complex modulates the cellular signaling of neurotensin in the ht29 cell line, Gastroenterology. 123 (2002) 1135-1143.

[47] Daub H, Weiss FU, Wallasch C, Ullrich A, Role of transactivation of the egf receptor in signalling by g-protein-coupled receptors, Nature. 379 (1996) $557-560$.

[48] Kolch W, Heidecker G, Kochs G, Hummel R, Vahidi H, Mischak H, 
Finkenzeller G, Marme D, Rapp UR, Protein kinase-c-alpha activates raf-1 by direct phosphorylation, Nature. 364 (1993) 249-252.

[49] Corbit KC, Trakul N, Eves EM, Diaz B, Marshall M, Rosner MR, Activation of raf-1 signaling by protein kinase $\mathrm{c}$ through a mechanism involving raf kinase inhibitory protein, J. Biol. Chem. 278 (2003) 13061-13068.

[50] Wojciechowski D, Vincenti F, Targeting jak3 in kidney transplantation: Current status and future options, Curr. Opin. Organ. Tran. 16 (2011) 614-619.

[51] Mijatovic T, Gailly P, Mathieu V, De Neve N, Yeaton P, Kiss R, Decaestecker $\mathrm{C}$, Neurotensin is a versatile modulator of in vitro human pancreatic ductal adenocarcinoma cell (pdac) migration, Cell. Oncol. 29 (2007) 315-326.

[52] Servotte S, Camby I, Debeir O, Deroanne C, Lambert CA, Lapiere CM, Kiss R, Nusgens B, Decaestecker C, The in vitro influences of neurotensin on the motility characteristics of human u373 glioblastoma cells, Neuropath. Appl. Neuro. 32 (2006) 575-584.

[53] Zhao DZ, Keates AC, Kuhnt-Moore S, Moyer MP, Kelly CP, Pothoulakis C, Signal transduction pathways mediating neurotensin-stimulated interleukin-8 expression in human colonocytes, J. Biol. Chem. 276 (2001) 44464-44471.

[54] Adachi T, Vita R, Sannohe S, Stafford S, Alam R, Kayaba H, Chihara J, The functional role of rho and rho-associated coiled-coil forming protein kinase in eotaxin signaling of eosinophils, J. Immunol. 167 (2001) 4609-4615.

[55] Belo A, Cheng KR, Chahdi A, Shant J, Xie GF, Khurana S, Raufman JP, Muscarinic receptor agonists stimulate human colon cancer cell migration and 
invasion, Am. J. Physiol-Gastr. L. 300 (2011) G749-G760.

[56] Umelo IA, Wever OD, Kronenberger P, Noor A, Teugels E, Chen G, Bracke M, Greve JD, Combined inhibition of rho-associated protein kinase and egfr suppresses the invasive phenotype in egfr-dependent lung cancer cells, Lung cancer. 90 (2015) 167-174.

[57] Fang Y, Frutos AG, Verklereen R, Label-free cell-based assays for gpcr screening, Comb. Chem. High. T. Scr. 11 (2008) 357-369.

[58] Fang Y, Label-free cell-based assays with optical biosensors in drug discovery, Assay. Drug. Dev. Techn. 4 (2006) 583-595.

[59] Tran E, Ye F, Duplexed label-free g protein--coupled receptor assays for high-throughput screening, J. Biomol. Screen. 13 (2008) 975-985.

[60] Fang Y, Live cell optical sensing for high throughput applications, Adv. Biochem. Eng. Biotechnol. 118 (2010) 153-163. 

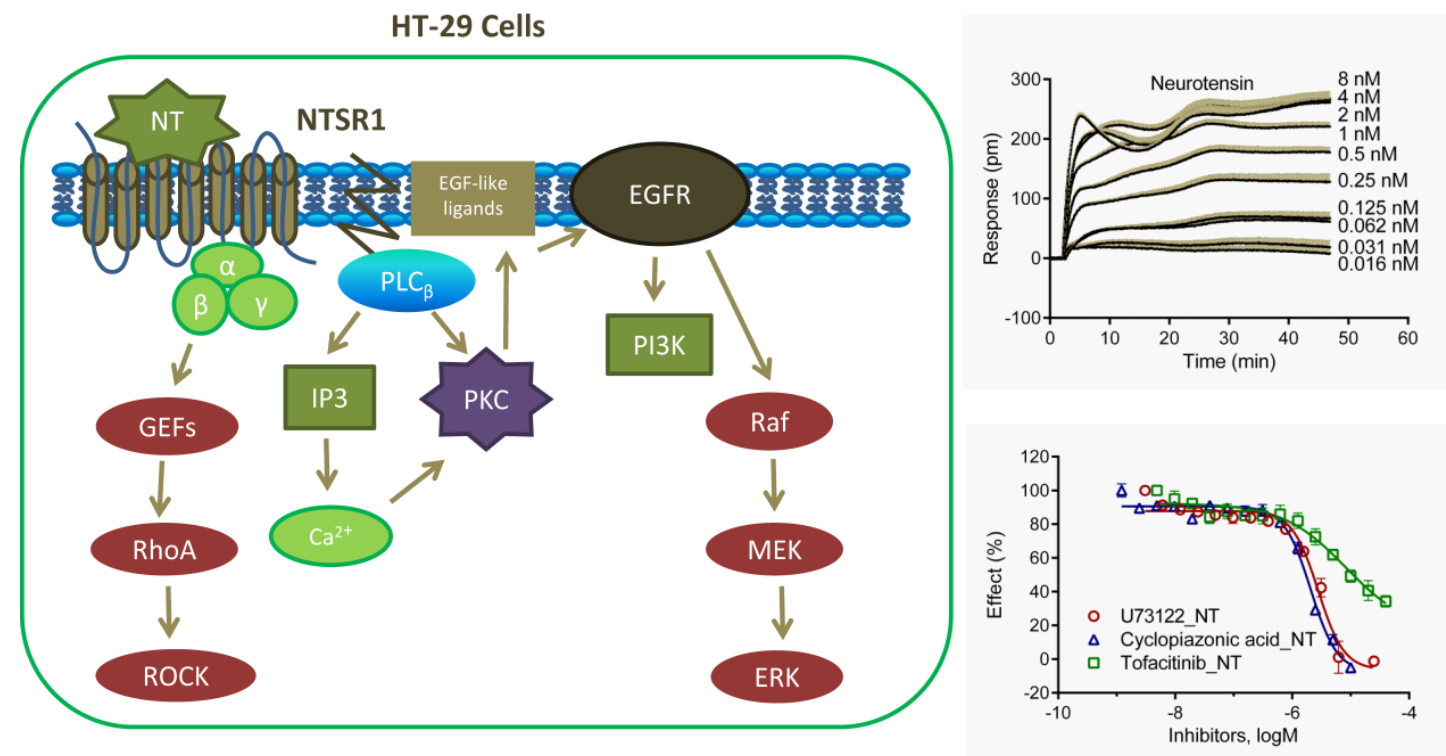